\title{
Undiscovered morphine. The effects of the long-term use of the opioids
}

\begin{abstract}
Morphine and other opioids are used much more often and for a longer time than before. This causes many relatively unknown adverse effects, which become apparent only after a while. One of them is opioid-induced hyperalgesia and abnormal magnesium metabolism. The adverse effect that negatively influences the quality of life is opioid-induced hypogonadism. Morphine can have a profound immunosuppressive and tumour-promoting effect. It is probably responsible for the increased rate of heart infarctions. Very interesting are suggestions that morphine and other opioids are changing the large bowel microbiome. All of these phenomena do not concern only few patients but are generalized in this population and the severity of the phenomenon depends only on the treatment period. Jet none of these adverse effects are mentioned in drug leaflets. All of these phenomena are treatable providing that the diagnose is made accurately and timely. It is very well possible that in the future we shall be able to prevent most of these adverse effects.

Palliat Med Pract 2019; 13, 1: 22-26

Key words: morphine, fentanyl, opioids, buprenorphine, opioid-induced hyperalgesia, hypogonadism, magnesium, osteoporosis, myocardial infarction, immunosuppression, induction of cancer growth, gut microbiome
\end{abstract}

\section{Introduction}

Morphine as a component of opium is known in medicine for 6,000 years. For more than 200 years it is used as a pure drug. Since the time morphine became a part of modern medicine, it is well known that considerable adverse effects always accompany its analgesic effect. These adverse effects like constipation, nausea and vomiting and deterioration of cognitive functions are known to every medical student. However, some of the adverse effects are less well known, and they are never mentioned on the drug leaflets. These adverse effects are not known at all and never discussed with the patients before the beginning of therapy. We use more and more opioids, not only for the control of pain in the course of the malignant disease [1].

Because patients with cancers live much longer than a couple of decades ago, probably they use opioids for a longer time than before. Formerly opioids were used for a couple of weeks to months only and this period invariably ended in the patients' death. Nowadays we have quite a large group of cancer survivors among whom opioids need to be used for a longer time, sometimes for years [2]. Above all, in the USA, and not only there, it also appears that there is a considerable group of patients treated with opioids for non-malignant conditions [1]. This all makes that we should think about the long-term effects of opioids.

\section{Corresponding address:}

Zbigniew Żylicz

Kopisto St. 2a, Rzeszów

e-mail: z.zylicz@ur.edu.pl 


\section{Tolerance and Hyperalgesia}

Tolerance to opioids is known to clinicians for decades. Opioids are very successful at the beginning. However, their efficacy diminishes rapidly. To obtain the same analgesic effects clinicians must increase the dose of the drug [3]. This phenomenon is rare when the treatment is short, for example postoperatively, but becomes considerable when the drug is used for a long while, especially in genetically susceptible patients [4]. In the past, some influential authors suggested that the opioid tolerance could be prevented by using it "by the clock", which means that the next dose should be administered before the effect of the first dose will wean [5].

Unfortunately, this way of administration was not entirely successful either. Continuous morphine and other opioids administration induce changes in glutaminergic transmission [6] and excitation of the $\mathrm{N}$-methyl-D-aspartase (NMDA) receptors [7]. These changes can be counteracted by the NMDA-inhibitor; ketamine $[8,9]$.

Tolerance to opioids has much in common with Opioid-Induced Hyperalgesia (OIH) which is defined as a nociceptive sensitisation caused by exposition to opioids [10]. The clinicians can easily mix up those two phenomena. In the case of $\mathrm{OIH}$, the opioid given to the patient not only causes analgesia but is the cause of a "new pain" due to the spinal excitation. If this "new pain" is not explicitly recognised it would cause, similarly to opioid tolerance, the need for an opioid dose increase. The differences between tolerance and $\mathrm{IOH}$ are discrete. This "new pain" maybe, but not necessarily, be similar to the original pain. The original pain may be already efficaciously treated by the opioid. The patient shows increased sensitivity to pain impulses [11]. Investigations on the large patient populations showed that patients treated with opioids are more sensitive to pain impulses compared to the patients treated with non-opioid analgesics [12]. The reader interested in the problems around $\mathrm{OIH}$ is referred to specific publications [13, 14].

Management of $\mathrm{OIH}$ is usually based on making a specific diagnosis and decrease of the opioid dose [15]. If this is impossible, or for the patient and its family counter-intuitive, the opioid may be switched from for example morphine or fentanyl to the opioids with less potential of producing $\mathrm{OIH}$ - buprenorphine [16] or methadone [17]. In any case, the clinicians should refrain from using the mega opioid doses[18], which were so popular only two decades ago. Another strategy could be the addition of NSAIDs or paracetamol [19].

\section{Hypogonadism induced by opioids}

Already after the first dose opioids inhibit the secretion of the pituitary gonadotrophins [20]. Prolonged opioid administration may lead to hypogonadism, as well in man as women [21-23]. Deficiency of testosterone and other sex hormones manifests itself as fatigue, anaemia, increased sensitivity to pain stimuli, muscular atrophy, osteoporosis, erectile and menstrual cycle dysfunction. In total, hypogonadosm translates into a lower quality of life of patients treated with opioids [24]. The management is straightforward and not very toxic. Terminally ill patients may be treated with testosterone [25]. However, it should be born in mind that testosterone deficiency may cause insensitivity to opioids [26]. Administration of testosterone rapidly changes this to increased sensitivity to opioids which may result in an unexpected respiratory depression [25]. It seems, for obvious reason, there is a consensus not to prescribe testosterone to patients with prostate and breast cancers.

\section{Osteoporosis}

Long term administration of opioids, probably induces bone decalcification and osteoporosis and decalcification translates in an increased risk of bone fractures $[27,28]$. However, in falls, other factors as weakness and disturbances of consciousness may play a role too.

\section{Disorders of magnesium metabolism}

Magnesium is one of the most critical ions involved in pain origination and transmission [29]. It plays a vital role in muscle and bone metabolism as well as in the metabolism of carbohydrates. Deficiency of this ion causes among others opening of the NMDA ion channels and promotes their activation [30] which translates in pro-nociceptive activity. Long term treatment with morphine causes increased renal magnesium excretion and hypomagnesaemia [31]. On the other hand, the administration of magnesium sulfate together with morphine considerably increases morphine analgesic effect [32]. In the meta-analysis of multiple trials with magnesium sulfate and morphine, this effect was confirmed beyond any doubt [32, 33].

\section{Effects of opioids on the tumour growth}

Morphine has an immunosuppressive effect and increases proliferation and migration of the tumour 
cells as well as it promotes tumour angiogenesis [34]. In this respect, morphine is the most immunosuppressive of all opioids [35] and least immunosuppressive is buprenorphine [36]. That in case of terminally ill the immunosuppressive effects of opioids is the least of concerns, but in many thousands of cancer survivors that need to be treated with analgesics for a long time, it may be of paramount importance.

\section{Nocturnal breathing disorders}

Patients treated with opioids for chronic pain have a high probability of nocturnal apnea and hypoxemia [37]. Resting hypoxemia can be observed in these patients also in the day time, especially after the awakening [37].

\section{Cardiovascular diseases}

Not much is known about the influence of opioids on cardiovascular diseases. In one large cohort covering 297314 patients [38], and receiving opioids for at least 180 days in 3.5 years the Adjusted Incidence Rate Ratio (AIRR) of myocardial infarction was moderately increased and equal to 2.66 (Cl, 2.30 to 3.08 ). Patients prescribed opioids at the cumulated MEDD (Morphine Equivalent Daily Dose) of $1350 \mathrm{mg}$ during 90 days the AIRR was $1.21(\mathrm{Cl}, 1.02$ to 1.45$)$ while the AIRR in patients treated with a MEDD between $1350-2700 \mathrm{mg}$ in 90 days was calculated as 1.42 up to 1.89 . These risk values are higher than the risk of myocardial infarction after treatment with ibuprofen of diclofenac [39].

\section{Gastrointestinal disorders}

Opioids are known to affect the delay in gastric emptying and slow the intestinal movements which result in increased nausea and vomiting as well as constipation. Opioids are also known to change the bacterial content of the large bowel [40]. In patients addicted to opioids, there is a remarkable deficit of Bifidus and Prevotella sp. bacteria. This phenomenon may influence the development of psychological depression [41] and cancer cachexia [42] as well as many other symptoms accompanying neoplastic diseases.

\section{Conclusions}

The consumption of opioids, including morphine, increases year by year. These data include not only the treatment of pain in the course of cancer but also the treatment of non-cancer pain. Some patients use morphine and other opioids for a more extended period. In this situation, it is essential to consider the long-term effects of treatment with morphine and other opioids. Besides well-known more or less acute adverse effects of morphine and other opioids, there are some less well-known long-term effects which are a problem only after more extended use.

The most important is the development of $\mathrm{OlH}$ and disturbance of magnesium metabolism and excretion. Here morphine is the cause of new pain and suffering, which without a specific diagnosis usually ends up in the increase of opioid dose and treatment failure. If the diagnosis of $\mathrm{OIH}$ is correctly made the first-choice treatment is decreasing and not increasing the dose. Another strategy is to swap one opioid of the higher $\mathrm{IOH}$ potential to buprenorphine or methadone.

After $\mathrm{OlH}$, the often occurring and rarely recognised hypogonadism is very important for the quality of life of patients. Here, we should probably sooner substitute with testosterone. In women, this can lead to unpleasant virilisation. It is essential, however, to realise that these adverse effects do not occur only in some but in virtually all patients. The extent of the phenomenon probably depends on genetics, dose and the duration of opioid treatment. It looks like buprenorphine has the most interesting profile in this aspect and is suitable as no one other opioid for the long term treatment [43]. Exciting is the change in microbiome in large bowel under the influence of opioids. Perhaps this is the key to the understanding of many ailments related to long-term use of opioids.

Does this all mean that we should use fewer opioids instead of more? Yes and No. For sure, where opioids can be replaced by other drugs or non-drugs methods of treatment, this should be done at once. On the other hand, physical rehabilitation in palliative medicine has great potential and should be further developed $[44,45]$. Intensive rehabilitation is associated with the reduction of opioid doses and decrease of intensity of pain [46]. On the other hand, we should not overreact, because still numerous patients remain undertreated with opioids.

\section{References}

1. Breivik H, Gordh T, Butler S. Keeping an open mind: Achieving balance between too liberal and too restrictive prescription of opioids for chronic non-cancer pain: Using a two-edged sword. Scand J Pain. 2012; 3(1): 1-4, doi: 10.1016/j.sjpain.2011.11.012, indexed in Pubmed: 29913761.

2. van den Beuken-van Everdingen M. Chronic pain in cancer survivors: a growing issue. J Pain Palliat Care Pharmacother. 2012; 26(4): 385-387, doi: 10.3109/15360288.2012.734908, indexed in Pubmed: 23216187.

3. Hayhurst CJ, Durieux ME. Differential Opioid Tolerance and Opioid-induced Hyperalgesia: A Clinical Re- 
ality. Anesthesiology. 2016; 124(2): 483-488, doi: 10.1097/ALN.0000000000000963, indexed in Pubmed: 26594912.

4. Roeckel LA, Le Coz GM, Gavériaux-Ruff C, et al. Opioid-induced hyperalgesia: Cellular and molecular mechanisms. Neuroscience. 2016; 338: 160-182, doi: 10.1016/j. neuroscience. 2016.06.029, indexed in Pubmed: 27346146.

5. Twycross RG. Morphine and diamorphine in the terminally ill patient. Acta Anaesthesiol Scand Suppl. 1982; 74: 128-134, indexed in Pubmed: 6953726.

6. Mao J, Sung B, Ji RR, et al. Chronic morphine induces downregulation of spinal glutamate transporters: implications in morphine tolerance and abnormal pain sensitivity. J Neurosci. 2002; 22(18): 8312-8323, indexed in Pubmed: 12223586.

7. Célèrier E, Laulin J, Larcher A, et al. Evidence for opiate-activated NMDA processes masking opiate analgesia in rats. Brain Res. 1999; 847(1): 18-25, indexed in Pubmed: 10564731.

8. Vadivelu N, Schermer E, Kodumudi V, et al. Role of ketamine for analgesia in adults and children. J Anaesthesiol Clin Pharmacol. 2016; 32(3): 298-306, doi: 10.4103/09709185.168149, indexed in Pubmed: 27625475.

9. Quibell $R$, Fallon $M$, Mihalyo $M$, et al. Ketamine. J Pain Symptom Manage. 2015; 50(2): 268-278, doi: 10.1016/j. jpainsymman.2015.06.002, indexed in Pubmed: 26096492.

10. Yi P, Pryzbylkowski P. Opioid Induced Hyperalgesia. Pain Med. 2015; 16 Suppl 1: S32-S36, doi: 10.1111/pme.12914, indexed in Pubmed: 26461074.

11. LeeMO. Opioid-induced hyperalgesia. J Clin Rheumatol. 2012; 18(7): 325-326, doi: 10.1097/RHU.0b013e3182733011, indexed in Pubmed: 23047531.

12. Samuelsen PJ, Nielsen CS, Wilsgaard T, et al. Pain sensitivity and analgesic use among 10,486 adults: the Tromsø study. BMC Pharmacol Toxicol. 2017; 18(1): 45, doi: 10.1186/s40360-017-0149-2, indexed in Pubmed: 28599683.

13. Yang DZ, Sin B, Beckhusen J, et al. Opioid-Induced Hyperalgesia in the Nonsurgical Setting: A Systematic Review. Am J Ther. 2018 [Epub ahead of print], doi: 10.1097/MJT.0000000000000734, indexed in Pubmed: 29726847.

14. Weber L, Yeomans DC, Tzabazis A. Opioid-induced hyperalgesia in clinical anesthesia practice: what has remained from theoretical concepts and experimental studies? Curr Opin Anaesthesiol. 2017; 30(4): 458-465, doi: 10.1097/ACO.0000000000000485, indexed in Pubmed: 28590258.

15. Zylicz Z, Twycross R. Opioid-induced hyperalgesia may be more frequent than previously thought. J Clin Oncol. 2008; 26(9): 1564; author reply 1565, doi: $10.1200 / \mathrm{JCO}$.2007.15.6919, indexed in Pubmed: 18349412.

16. Koppert W, Ihmsen H, Körber N, et al. Different profiles of buprenorphine-induced analgesia and antihyperalgesia in a human pain model. Pain. 2005; 118(1-2): 15-22, doi: 10.1016/j.pain.2005.06.030, indexed in Pubmed: 16154698.

17. Axelrod DJ, Reville B. Using methadone to treat opioid-induced hyperalgesia and refractory pain. J Opioid Manag. 2007; 3(2): 113-114, indexed in Pubmed: 17520991.

18. Kaye AD, Alian AA, Vadivelu N, et al. Perioperative dilemma: challenges of the management of a patient on mega doses of morphine and methadone. J Opioid Manag. 2014; 10(1): 69-72, doi: 10.5055/jom.2014.0194, indexed in Pubmed: 24604572.

19. Ramasubbu C, Gupta A. Pharmacological treatment of opioid-induced hyperalgesia: a review of the evidence.
J Pain Palliat Care Pharmacother. 2011; 25(3): 219-230, doi: 10.3109/15360288.2011.589490, indexed in Pubmed: 21834699.

20. Grossman A, Moult PJ, Cunnah D, et al. Different opioid mechanisms are involved in the modulation of ACTH and gonadotrophin release in man. Neuroendocrinology. 1986; 42(4): 357-360, doi: 10.1159/000124463, indexed in Pubmed: 3008020.

21. Reddy RG, Aung T, Karavitaki N, et al. Opioid induced hypogonadism. BMJ. 2010; 341: c4462, doi: 10.1136/bmj. c4462, indexed in Pubmed: 20807731.

22. Hochberg U, Ojeda A, Brill S, et al. Opioid-induced hypogonadism: why and how to treat it. Pain Physician. 2012; 15(3 Suppl): ES111-ES118, indexed in Pubmed: 22786450.

23. Fountas $A$, Chai ST, Kourkouti $C$, et al. MECHANISMS IN ENDOCRINOLOGY: ENDOCRINOLOGY OF OPIOIDS. Eur J Endocrinol. 2018 [Epub ahead of print]; 179(4): R183-R196, doi: 10.1530/EJE-18-0270, indexed in Pubmed: 29973378.

24. Zylicz Z. Opioid-induced hypogonadism: the role of androgens in the well-being and pain thresholds in men and women with advanced disease. Adv Pall Med. 2009; 8: 57-62.

25. Raheem OA, Patel SH, Sisul D, et al. The Role of Testosterone Supplemental Therapy in Opioid-Induced Hypogonadism: A Retrospective Pilot Analysis. Am J Mens Health. 2017; 11(4): 1208-1213, doi: $10.1177 / 1557988316672396$, indexed in Pubmed: 28625114.

26. Brennan MJ. The effect of opioid therapy on endocrine function. Am J Med. 2013; 126(3 Suppl 1): S12-S18, doi: 10.1016/j.amjmed.2012.12.001, indexed in Pubmed: 23414717.

27. Vestergaard P, Rejnmark L, Mosekilde L. Fracture risk associated with the use of morphine and opiates. J Intern Med. 2006; 260(1): 76-87, doi: 10.1111/j. 1365-2796.2006.01667.x, indexed in Pubmed: 16789982.

28. Li L, Setoguchi S, Cabral H, et al. Opioid use for noncancer pain and risk of fracture in adults: a nested case-control study using the general practice research database. Am J Epidemiol. 2013; 178(4): 559-569, doi: 10.1093/aje/kwt013, indexed in Pubmed: 23639937.

29. Ahmadi S, Golbaghi H, Azizbeigi R, et al. N-methyl-D-aspartate receptors involved in morphine-induced hyperalgesia in sensitized mice. Eur J Pharmacol. 2014; 737: 85-90, doi: 10.1016/j.ejphar.2014.04.048, indexed in Pubmed: 24842190

30. Durlach J, Bac P, Bara M, et al. Physiopathology of symptomatic and latent forms of central nervous hyperexcitability due to magnesium deficiency: a current general scheme. Magnes Res. 2000; 13(4): 293-302, indexed in Pubmed: 11153899

31. Vachon M, Marchand C. Plasma magensium concentration and urinary magnesium excretion in rats treated chronically with morphine. Toxicol Appl Pharmacol. 1971; 19(4): 610-616, indexed in Pubmed: 5132031.

32. Begon S, Pickering G, Eschalier A, et al. Magnesium increases morphine analgesic effect in different experimental models of pain. Anesthesiology. 2002; 96(3): 627-632, indexed in Pubmed: 11873038.

33. Murphy JD, Paskaradevan J, Eisler LL, et al. Analgesic efficacy of continuous intravenous magnesium infusion as an adjuvant to morphine for postoperative analgesia: a systematic review and meta-analysis. Middle East J Anaesthesiol. 2013; 22(1): 11-20, indexed in Pubmed: 23833845.

34. Gach K, Wyrębska A, Fichna J, et al. The role of morphine in regulation of cancer cell growth. Naunyn Schmiedebergs Arch Pharmacol. 2011; 384(3): 221-230, doi: 10.1007/s00210-011-0672-4, indexed in Pubmed: 21800094. 
35. Mellon RD, Bayer BM. Evidence for central opioid receptors in the immunomodulatory effects of morphine: review of potential mechanism(s) of action. J Neuroimmunol. 1998; 83(1-2): 19-28, indexed in Pubmed: 9610669.

36. Sacerdote P. Opioid-induced immunosuppression. Curr Opin Support Palliat Care. 2008; 2(1): 14-18, doi: 10.1097/SPC.0b013e3282f5272e, indexed in Pubmed: 18685388.

37. Mogri $M$, Desai $H$, Webster $L$, et al. Hypoxemia in patients on chronic opiate therapy with and without sleep apnea. Sleep Breath. 2009; 13(1): 49-57, doi: 10.1007/s11325008-0208-4, indexed in Pubmed: 18683000.

38. Carman WJ, Su S, Cook SF, et al. Coronary heart disease outcomes among chronic opioid and cyclooxygenase-2 users compared with a general population cohort. Pharmacoepidemiol Drug Saf. 2011; 20(7): 754-762, doi: 10.1002/pds.2131, indexed in Pubmed: 21567652.

39. Hippisley-Cox J, Coupland C, Logan R, et al. Risk of myocardial infarction in patients taking cyclo-oxygenase- 2 inhibitors or conventional non-steroidal anti-inflammatory drugs: population based nested case-control analysis. BMJ. 2005; 330(7504): 1366-1316, doi: 10.1136/bmj.330.7504.1366, indexed in Pubmed: 15947398.

40. Barengolts $E$, Green SJ, Eisenberg $Y$, et al. Gut microbiota varies by opioid use, circulating leptin and oxytocin in African American men with diabetes and high burden of chronic disease. PLoS One. 2018; 13(3): e0194171, doi: 10.1371/journal.pone.0194171, indexed in Pubmed: 29596446.
41. Pandey GN, Rizavi HS, Bhaumik R, et al. Toll-like receptors in the depressed and suicide brain. J Psychiatr Res. 2014; 53: 62-68, doi: 10.1016/i.jpsychires.2014.01.021, indexed in Pubmed: 24565447.

42. Kawai T, Akira S. The role of pattern-recognition receptors in innate immunity: update on Toll-like receptors. Nat Immunol. 2010; 11(5): 373-384, doi: 10.1038/ni.1863, indexed in Pubmed: 20404851.

43. Likar R, Kayser H, Sittl R. Long-term management of chronic pain with transdermal buprenorphine: a multicenter, open-label, follow-up study in patients from three short-term clinical trials. Clin Ther. 2006; 28(6): 943-952, doi: 10.1016/j.clinthera.2006.06.012, indexed in Pubmed: 16860176 .

44. Wittry SA, Lam NY, McNalley T. The Value of Rehabilitation Medicine for Patients Receiving Palliative Care. Am J Hosp Palliat Care. 2018; 35(6): 889-896, doi: 10.1177/1049909117742896, indexed in Pubmed: 29179573.

45. Lee $\mathrm{CH}$, Kim JK, Jun $\mathrm{HJ}$, et al. Rehabilitation of Advanced Cancer Patients in Palliative Care Unit. Ann Rehabil Med. 2018; 42(1): 166-174, doi: 10.5535/arm.2018.42.1.166, indexed in Pubmed: 29560337.

46. Sabiston CM, Brunet J, Burke S. Pain, movement, and mind: does physical activity mediate the relationship between pain and mental health among survivors of breast cancer? Clin J Pain. 2012; 28(6): 489-495, doi: 10.1097/AJP.0b013e31823853ac, indexed in Pubmed: 22673481. 